The Geneva Papers on Risk and Insurance, 20 (No. 76, July 1995) 325-335

\title{
Natural Hazards as the Cause of Toxic Spills in the United States, with some Notes on Liability*
}

\author{
by Pamela S. Showalter**
}

\begin{abstract}
Summary
Natural disasters that create technological emergencies by causing the release of dangerous materials such as oil, chemicals, or radiological/infectious agents are called "na-tech" events (Showalter and Myers 1992). Although there has yet to be a catastrophic na-tech event in the United States, low impact events are fairly common. An example of this occurred a few weeks ago when, during flooding in Texas, an oil pipeline ruptured by floodwaters exploded. The potential for a serious na-tech event is rising, however, bacause the US, like many industrialized countries, is greatly dependent on the production and use of chemicals. For example, industry manufactures millions of gallons of gasoline and millions of pounds of herbicides every day. Additionally, in 1985, approximately 200,000 facilities in the US generated 275 million metric tons of hazardous waste. Many of these facilities, as well as those that store, transport, and/or use such toxic materials, are vulnerable to the different types of natural hazards that exist in a country as large as the US.

In an effort to obtain baseline data regarding na-tech events that occurred in the past, and to estimate their potential for the future, the Natural Hazards Research and Applications Information Center (University of Colorado-Boulder) performed a literature search and surveyed US state emergency management agencies. Among the findings was a clear trend toward increasing numbers of na-tech events, with the largest promotion of incidents involving interaction with earthquakes, followed by climatic-related events such as hurricanes, floods, lightning, and winds. However, only rarely was evidence presented that governmental policies or legislation directly recognized the possibility for such events.

Part of the reason that na-tech events are not addressed directly is because disaster planning tends to be "agent-specific" with separate, distinct plans organized around specific natural agents, such as floods, or artificial agents, such as hazardous material releases. Because of this, emergency planners rarely prepare for na-tech events, per se, instead relying on guidelines in agent-specific documents (such as are found in the National Flood Insurance Program) to reduce the impact of such events.
\end{abstract}

* Paper presented at the MORE 10-Seminar in Courbevoie, France, November 1994.

** Assistant Professor, Department of Geography and Planning, University of Toledo, Ohio, USA. 
The Hazard Center's survey asked emergency planners for recommendations to reduce damage from future na-tech events. Among the recommendations was a desire to engage the insurance industry via a long-term program to adjust insurance rates so that they reflect the adoption of mitigation measures that minimize the potential for disaster-generated damages, economic losses, and injuries. This paper identifies some of the options, and obstacles, that currently face the insurance industry when it attempts to deal with natural or technological events, and endeavors to relate these issues to na-tech events.

\section{Introduction}

When a natural disaster acts as the catalyst for the creation of a hazardous material (hazmat) release, it is referred to as a "na-tech" event (Showalter and Myers 1992). While the United States (US) has yet to be the victim of a catastrophic na-tech event, low-impact episodes are common. Household propane tanks often become floating mines during heavy flooding, fuel leaking from earthquakes-ruptured gas lines can ignite, and winds from a variety of storms damage or destroy hazmat storage containers.

An example of a large scale na-tech event that took place outside the US occurred in 1987 in Edmonton, Canada. In July of that year, a tornado developed and remained in contact with the ground for 64 minutes, moving through an industrial area. Many road vehicles, large and small storage tanks and propane tanks, assorted containers, and natural gas lines were damaged and ruptured. Some of the toxins that were released onto the ground or into the air that day included liquid oxygen and other cryogenic products, diesel fuel, liquid asphalt, herbicides (such as 2,4-D), anhydrous ammonia, bulk gaseous oxygen, acetylene, chlorine, infectious substances, radioactive materials, and polychlorinated biphenyls (PCBs). Fortuitously, while the tornado passed between four large oil refineries and within 1500 meters of three world-scale chemical plants, it inflicted only minor damage on these facilities (Showalter and Myers 1992).

There was significant potential for the Edmonton tornado, one of Canada's worst natural disasters, to become a catastrophic na-tech event. The US is equally susceptible to such an incident, for this country, like many of its industrialized neighbors, is greatly dependent on the production of chemicals. For example, industries manufacture millions of gallons of gasoline and millions of pounds of herbicides every day (Tierney 1988). Additionally, in 1985, approximately 200,000 facilities in the US generated 275 million metric tons of hazardous waste (US General Accounting Office 1991). The generation of so much waste has led, in turn, to there being an estimated 32,000 to 50,000 known hazardous waste dumps scattered throughout the country (Ziegler et al. 1983).

Many of the facilities described above, as well as those that store, transport, and/or use such toxic materials, are vulnerable to the different types of natural hazards that exist in a country as large as the US. These facilities include lifelines that carry gas and liquid fuel. As potential agents of hazardous material releases in the event of a natural disaster, lifeline vulnerability was recently characterized as: high for earthquakes, moderate for tornados, and low for both hurricane and flood (National Institute of Building Sciences 1989). Unfortunately, while some regulatory steps are being taken at the federal and state level, they usually do not include (with some exceptions) regulating “...the design and construction of ...facilities located in areas vulnerable to natural hazards such as flooding" (Pennsylvania Department of Community Affairs 1988, p. 1). The consequence of such lack of regulation was exhibited recently during floods in Texas. An oil pipeline located within the floodplain that 
was not shut off (despite the flooding), ruptured and exploded. Fortunately, no one was killed or injured in this incident, but additional - and avoidable - property damage was incurred.

One of the problems in establishing regulatory or policy measures for na-tech events is a lack of data. Currently, large documents only give cursory recognition to the existence of na-tech events (e.g., Federal Emergency Management Agency 1990, pp. 27, 30, 74; Huey 1990, pp. 1J, 4K). Hopefully, such a lack of recognition may not persist. Recent earthquakes and hurricanes in the US and the Virgin Islands have caused spills or releases of petroleum, chemicals (propane, ammonia, formaldehyde, maiathion, chlorine, cyanide, acid and highly acidic water, hydrogen gas, natural gas), raw sewage, and asbestos (Showalter and Myers 1992). After Hurricane Hugo, contingency planners on St. Croix, who had previously focused their response strategy around a worst case scenario involving a 1.5 million barrel catastrophic tanker grounding, replaced that scenario"... by a 14 million barrel catastrophic destruction of the ... (oil) tank farm ... no one can view the destruction of the ... tank fields wrought by the fury of Hurricane Hugo and fail to recognize the awesome potential for disaster" (Bills and Whiting 1990, p. 182).

\section{Some findings of the na-tech survey}

Responding to, or mitigating the effects of, a na-tech event is more complex than responding to natural or hazmat events individually. Therefore it is important to confront the issue before a significant na-tech event takes place. However, since na-tech events are currently perceived to have minor effects and/or to be sufficiently mitigated at the local level, a lack of standardized record-keeping regarding such events makes it difficult to accurately determine their frequency and the extent of their impacts.

In an effort to obtain baseline data regarding previous na-tech events in the US, and to estimate their potential for the future, the Natural Hazards Research and Application Information Center (University of Colorado-Boulder) performed a literature search and surveyed US state emergency management agencies (Showalter and Myers 1992). Although many states were unable to respond to the survey, data acquired from others allowed for the identification of some trends. The following comments and figures related to this survey are excerpted from an article based on the 1992 research, that appeared in the journal, Risk Analysis (Showalter and Myers 1994).

\subsection{Causative agents}

Among the questions on the survey, respondents were asked to list for the years 19801989 , known na-tech events in their states involving the release of chemicals, oils, or radiological materials. The largest number of na-tech events were precipitated by earthquakes, followed by climatic-related events such as hurricanes, floods, lightning, winds, and storms (Figure 1). This finding is significant because, at the national level, floods are the most common natural disaster and they also represent the largest portion of annual damage (in terms of property loss).

\subsection{Number of events}

A clear trend toward increasing numbers of na-tech events was established, and is illustrated in Figure 2. Removing the large numbers of releases caused by Hurricane Hugo and the Loma Prieta earthquake from the 1989 data does not alter this trend. Three possible explanations for the increase are: 
Figure 1: Natural agents causing hazmat spills, 1980-1989

\section{NA-TECH INCIDENTS BY TYPE 20 STATES REPORTING $1980-1989$}

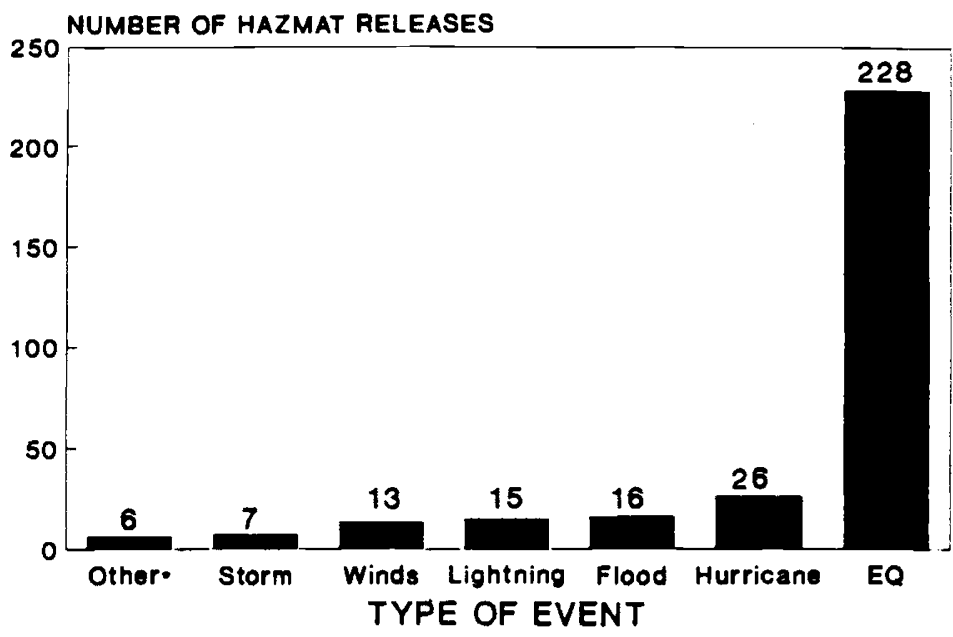

Figure 2: Number of na-tech events, 1980-1989
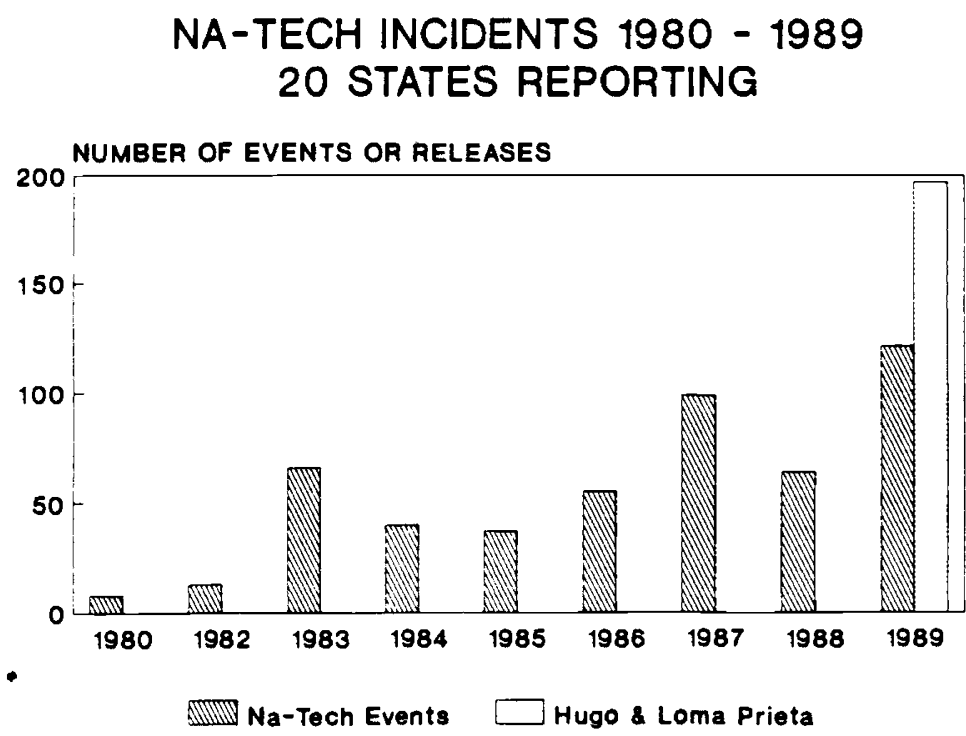
1) improved reporting procedures. None of states supplying answers indicated that their recordkeeping of such events had changed or improved toward the end of the decade (although this possibility cannot be ruled out since respondents were not explicitly asked about this on the survey);

2) an increase in absolute numbers of natural hazards events. There is no evidence indicating that the number of recorded natural hazard events is increasing, or;

3) there is an actual increase in na-tech events.

\subsection{Lack of legislative recognition}

The survey also confirmed what was discovered during the literature search, that there was little indication of legislation specifically designed to address the possibility of na-tech events. Frequently, guidelines such as those contained within the National Flood Insurance Program were cited by emergency managers as indirectly useful. One reason na-tech events have yet to be addressed by legislative bodies may be the simple novelty of the concept, but this finding indicates another reason is that existing legislation is often interpreted as addressing na-tech events indirectly, through codes and laws enacted for other reasons.

\subsection{Impressions of state susceptibility}

After providing records of their state's na-tech events, survey respondents were asked to rank, on a scale from 1-5, their impressions of their state's susceptibility to a significant na-tech event. From this data it was possible to identify a link between the availability of accurate records and respondent impressions of susceptibility. Respondents who had access to data regarding na-tech events in their states reported higher susceptibility rankings. Those who ranked susceptibility higher also considered current regulations insufficient (for a variety of reasons) given the increasing number of hazardous materials being generated and transported across the country.

\subsection{Respondent suggestions}

Finally, respondents were asked for recommendations to help mitigate the effects of future na-tech events. The most popular mitigation suggestion was a call for regulatory measures. For example, enforcing and/or developing siting restrictions or guidelines for building or storing hazmats in hazardous areas (e.g., floodplains) by requiring facilities utilizing or storing materials in a floodplain to comply with National Flood Insurance Program, state, and local standards related to the 100-year base flood zone. The desire for regulatory measures is understandable since they: 1) document the seriousness with which various levels of government view the problem; 2) provide rigorous guidelines regarding acceptable activity; and 3 ) empower the emergency manager with the ability to monitor compliance (if accompanied by appropriate funding). However, it would probably be difficult to convince legislators to enact new regulatory policies while current data on na-tech events remains limited.

Another suggestion was to "engage" the insurance industry. A long-term program was envisioned, whereby insurance rates would be adjusted to reflect the adoption of mitigation measures that minimize the potential for disaster-generated damages, economic losses, and injuries. Such a suggestion is worthwhile since, although the potential for a na-tech event may be low in an absolute sense, the threat is real and should a large incident occur its 
consequences are likely to be quite serious (Tierney 1989). Insurers wishing to be proactive toward na-tech events can learn from the current experiences of the US chemical industry, where,

"the increase in commercial production, distribution and use of hazardous materials has led to an increase in actual and perceived risks, and to a rising spiral of claims against [US] industry and insurers ... [who, along with industrial producers and users of hazardous substances] are increasingly vulnerable to economic losses from liability determinations ... and from more stringent government actions in all industrial nations" (Baram 1987, p. 416).

\section{Scale of losses and issues of insurability}

Currently, much disaster planning tends to be "agent-specific" with separate, distinct plans organized around specific natural agents, such as floods, or artificial agents, such as hazardous material releases (Quarantelli 1990). Similarly, insurance policies tend to deal with natural and technological events separately. Because the recognition of na-tech events is fairly recent, the following discussion will describe the magnitude of national losses due to natural disasters alone, and will introduce some insurance issues when dealing with natural or technological events.

\subsection{Losses}

Annually, natural hazards cost US state and local governments nearly $\$ 1$ billion in damage to public facilities. Between January 1, 1980 and December 31, 1985, "national infrastructure losses may have been as great as $\$ 5$ billion" (Burby 1991, p. 2). Most of these damages are not covered by insurance, and most are not covered by federal disaster assistance.

While the figures cited above are substantial, they represent only a fraction of US state and local governments' $\$ 2$ trillion capital stock. The implications of this fact are twofold: 1) through appropriate public policy, public losses should be financially manageable, and 2) current losses" ...may not be large enough to attract the attention of policy makers or to stimulate serious consideration of alternatives to the current approach to dealing with them" (Burby 1991, p. 46). The latter point is certainly pertinent to the lack of consideration currently being paid to na-tech events. Unfortunately,

“... while only a small proportion of publicly owned capital stock is at risk from natural hazards, losses can be truly catastrophic for a small number of govenments at the center of large natural disasters. [Therefore,] any scheme designed to deal with the financial impacts of public losses from natural hazards must be designed to deal with those rare, but very large, loss occurrences" (Burby 1991, p. 46).

It is this paper's contention that na-tech events deserve to be included in any such scheme.

Currently, state and local governments assume a majority of the risk loss. Alternatively they could relocate infrastructure out of harm's way, abandon highly vulnerable locations, retrofit existing facilities and/or design new ones to be less susceptible to damage, however all of these options are expensive. Another option involves risk transfer. This includes federal disaster assistance in the case of catastrophic events, and insurance, a vehicle whose availability is not guaranteed and which is used infrequently (Burby 1991). 


\subsection{Insurance undersubscription}

In the context of providing disaster assistance, insurance programs are more consistent than loans (which are susceptible to the vagaries of political expediency), producing "lower differences in incomes and wealth distribution among victims and between victims and taxpayers" (Comptroller General of United States 1980, in Burby 1991, p. 15). Yet, the choice of insuring against natural hazards is largely being ignored by local governments. This lack of interest in insurance may, at first, seem puzzling, but there are a variety of reasons for its being undersubscribed. For example, in the Disaster Relief Act of 1974, which allowed local governments to receive federal aid for losses to uninsured facilities, Congress also stipulated, as an incentive for localities to acquire hazards insurance, that subsequent insurable losses would not receive aid. This incentive is not working partly because the provision, which may be of interest to local governments that have experienced a disaster, "does little to foster mitigation among the thousands of local governments that have not experienced a disaster" (Burby 1991, p. 13). Other reasons for a lack in interest in insurance are: costs are inadequately contained, policies do not provide enough incentive for governments to adopt measures to prevent or even minimize increased exposure, legislative policies inequitably reward imprudent behavior (e.g., redistributing tax resources from poor to wealthy states), and because insurance is simply unavailable for much of the infrastructure vulnerable to natural disasters (Burby 1991).

\subsection{Effect of disaster relief:}

The existence of federal disaster relief may also affect decisions whether to purchase or forego insurance. The availability of disaster assistance may lead decisionmakers to ignore or underestimate hazards when deciding upon the location of public facilities, and may otherwise discourage the adoption of other mitigation measures (Burby 1991). In a similar manner, experience has shown that in California, where earthquakes are fairly common:

...the bulk of disaster relief (low interest) loans to small business and to homeowners ... provide ... an interest rate windfall ... (and) neither earthquake insurance nor loss reduction action is required as a condition of these loans. Consequently, as with some other disaster relief policies, there is no financial incentive for prospective victims to take prudent preventive action either through insurance or other forms of risk reduction (Alesch et al. 1993, p. 149).

\subsection{The role of risk managers:}

Risk managers may contribute to the undersubscription of insurance since they tend to underestimate the probability of experiencing loss from a natural hazard. Where an individual's experience with a disaster generally leads to the purchase of property insurance, for a risk manager the perception of the risk plays a greater role. Part of this difference is undoubtedly a function of local government personnel turnover; "the person making insurance decisions today may not even be aware of the losses his or her government experienced in a natural disaster some years earlier" (Burby 1991, pp. 112-113).

But, providing the risk manager with sufficient information regarding previous disasters does not guarantee that insurance will be purchased. It has been found that "if policy makers want to persuade a higher proportion of risk managers to acquire insurance against flooding and earthquakes, information needs to be more compelling than that presently available..." (Burby 1991, p. 113). 


\subsection{Lack of interest from insurance companies:}

Another reason insurance is undersubscribed may come from the insurance companies, themselves. Available data suggests that many US insurance firms "could suffer substantial losses from a major earthquake ... (due to) claims ... from indirect losses such as fire and workers compensation which are covered by non-earthquake policies" (Kunreuther 1993, p. 191).

Insurance companies willing to write homeowner earthquake coverage are very concerned about a major earthquake's impact on their financial condition. Following such an event, the surplus or net worth of most companies could be so reduced that they would be forced to restrict coverage on all insurance lines. Smaller firms could become insolvent. Interestingly, it is not the amount of earthquake insurance currently marketed that is of concern, so much as the fact that much of the projected earthquake damage and loss will fall under the auspices of other insurance policies that cover such things as business interruption, workers compensation and general liability. Therefore, even if earthquake coverage were completely discontinued by the industry, "it would still suffer considerable financial losses because it would be forced to pay claims from these other policies... "(Kunreuther 1993, p. 193). ${ }^{1}$

Furthermore, while the premiums that reinsurers believe that they can charge for a low probability catastrophic earthquake are relatively small, the losses if such an event were to take place could be enormous. Therefore,

"it is surprising that reinsurance for potential property loss from major natural disasters, such as earthquakes, is expensive and extremely difficult to obtain today, with companies, like Lloyd's of London, greatly reducing its potential exposure" (Kunreuther 1993, p. 202).

\subsection{Limited benefits of insurance:}

A final reason that may be hindering the procurement of insurance by governments is that the insurance that is available (e.g., flood and earthquake insurance for public buildings), only covers a small portion (less than $5 \%$ ) of potential state and local government losses. In other words, even if local governments had $100 \%$ subscription to insurance, federal disaster relief costs would not be greatly affected (Burby 1991).

Insuring against events such as automobile accidents or fires is relatively simple. Such incidents are sufficiently common that approximate risk and appropriate premiums can be calculated. Natural and technological disasters are another matter, for

"as [the] world's societies and the global economy continue to be more interdependent and more tightly coupled and as we deal with increasingly complex technologies, the number and kinds of low probability-high consequence risk grows. It is necessary to ascertain which kinds of insurance concepts and instruments make sense under various circumstances. It may even be necessary to create new insurance approaches (Alesch et al. 1993, p. 155)."

\footnotetext{
${ }^{1}$ One way insurers could protect themselves from such great losses would be to adopt the Japanese model of earthquake insurance, where they would only have to pay shake and indirect losses to earthquake policyholders of record. However, in the US, such a model is unlikely to be approved by state insurance commissioners (Kunreuther 1993).
} 
It is beyond the scope of this paper to address the myriad different insurance options in any detail. However, the potential advantages and disadvantages of three types of insurance (commercial insurance, self-insurance, and insurance pooling) will be briefly discussed.

\subsection{Commercial insurance}

Governments commonly transfer risk through the purchase of commercial insurance. Unfortunately, currently available commercial property insurance is not a satisfactory alternative to federal relief. First, commercial insurance tends to be expensive because it includes the overhead costs and profits of the insuring firm, which sometimes are as much as $40 \%$ of the premium (Burby 1991). Second, while property insurance is usually available for building, bridge, and public utility loss due to natural hazards, these losses account for less than $10 \%$ of the losses experienced by state and local governments. Other major categories (highways, debris removal, emergency protective measures, water control facilities) are rarely insured by the private market (Burby 1991).

\subsection{Self insurance}

Self insurance programs use annual appropriations of money to pay for losses, and are commonly used for worker's compensation and employee benefit programs, and (to some extent) for property, group life and short-term liability (Burby 1991).

Self insurance's feasibility is largely determined by three issues:

1) A jurisdiction's financial resources, since a funded reserve must be created. The program will be most cost efficient "if sufficient reserves exist to set up the plan immediately, because of the income earnings of the reserve" (Burby 1991, p. 67).

2) A jurisdiction's ability to estimate future losses. The viability of self insurance hinges on a government's ability to accurately predict future losses. Therefore, "special provisions should be made for catastrophic events (high severity risks) and recurrent events (high frequency events)" (Burby 1991, p. 67).

3) The cost effectiveness of the program. "Self insurance tends to promote better loss control because governments are acutely aware of the cost of losses" (Burby 1991, pp. 67-68).

Self insurance is not without problems, however. Legal authority must be provided to incur debt to fund the reserve and to carry over balances from year to year. Past experience has shown that public officials may access a reserve fund to pay for other projects, with the result that, due to the unpredictability of natural events and the size of potential losses, the reserve may be underfunded when it is needed (Burby 1991). Additionally, while self insurance may be viable for larger local governments, most small units do not possess "the financial capacity to assume large risks. Smaller governments can increase their ability to manage risk ... by pooling their funds with other governments" (Burby 1991, p. 69).

\subsection{Insurance pooling}

A relatively recent development (since 1974), insurance pooling requires the cooperation of several governmental entities that act as a group to handle the risks of accidental loss. This combined effort expands the exposure base, making losses more predictable and 
spreading the risks, which leads to a lower pro-rata share of costs for each participant. Insurance pooling can be found at local, state, regional, and inter-state levels and is commonly used for workers' compensation and health insurance (Burby 1991).

Some of the advantages of pools include: low/stable costs, enhanced control over insurance services, and access to professional management services. Some of the disadvantages include: the need to relinquish individual governmental control to the group, "joint and several liability" - where an individual governmental unit is responsible for losses of another governmental unit, and the fact that long-term membership in a pool may be obligatory - meaning that some payment terms may require members be assessed for payments to the pool even if they have withdrawn from the pool (additionally, in the case of withdrawal, governments may have to relinquish any claims to pool assets) (Burby 1991).

It has been suggested that insurance mechanisms that provide alternatives to disaster relief may need to be developed by the public sector, but may also need to be administered through a public/private partnership similar to the National Flood Insurance Program. Another alternative is to continue, but reform, current programs based on federal assistance for large disasters, including increased assumption of losses by local governments, and the formulation of new insurance mechanisms (e.g., insurance pools, expansion of federal insurance programs) (Burby 1991).

None of the three insurance options discussed above can, individually, answer the needs of governments and firms in the face of a na-tech event. However, given the size of a projected catastrophic na-tech event, a preferable insurance mechanism would probably be one that spreads the risk among as many units as possible. Perhaps a creative combination of the attributes of the above options, as well as others, may be used to establish some form of insurance response, where none currently exists.

\section{Conclusion}

Insurers have a special influence over industrial firms since those firms need affordable insurance. Thus, insurers could conceivably require, as a condition of obtaining insurance, "manufacturers, shippers, users, and disposers of hazardous materials develop and use improved methods of risk analysis, ${ }^{2}$ health and environmental monitoring, and safety engineering to reduce hazards and prevent risks and consequent liability" (Baram 1987, p. 418). The methods of risk analysis should include the potential for na-tech events. Currently, the US, as well as the countries of Western Europe, are encouraging chemical firms to conduct coherent and detailed risk analyses of their facilities to evaluate and prevent accident hazards and to promote community response or damage control plans (Baram 1987). If the insurance industry wishes to reduce its exposure to na-tech events, it could require each firm to evaluate the na-tech risks to which it is vulnerable. This would be a first step toward the explicit recognition of the potential for na-tech events and could lead to important policies that could reduce future loss, not only to insurance firms and insured industries, but to the public at large.

2 Risk analysis"...is the process of identifying potential hazards for individuals and society, and estimating their magnitude and probability of occurrence with the aid of statistics, experiments, analytic methods of various fields of science and engineering, human experience, and judgement" (Baram 1987, p. 429). 


\section{REFERENCES}

ALESCH, D.J., TAYLOR, C., GHANTY, A.S. and NAGY, R.A., "Earthquake Risk Reduction and Small Business", in Socioeconomic Impacts, Monograph No. 5, May 1993, National Earthquake Conference: An Activity of the International Decade for Natural Disaster Reduction, pp. 133-160, Memphis, Tennessee

BARAM, M.S., "Chemical Industry Hazards: Liability, Insurance, and the Role of Risk Analysis", in Insuring and Managing Hazardou Risks: From Seveso to Bhopal and Beyond, P.R. Kleindorfer and H.C. Kunreuther, editors, 1987, pp. 415-441, New York: Springer-Verlag.

BILLS, C.E. and WHITING, D.C., "Major Oil Spills, St Croix, U.S. Virgin Islands", in Oil Spills: Management and Legislative Implications, Proceedings of the Conference, Newport, Rhode Island, May 15-18, 1990, New York: American Society of Civil Engineers.

BURBY, R.J., Sharing Environmental Risks: How to Control Governments' Losses in Natural Disasters, With B.A. Cigler, S.P. French, E.J. Kaiser, J. Kartez, D. Roenigk, D. Weist and D. Whittington. Boulder, Colorado: Westview Press.

Disaster Research, October 14, 1994, No. 148, Electronic Bulletin Board moderated by the Natural Hazards Research and Applications Information Center. Boulder, Colorado: University of Colorado. HAZCTR COLORADO. EDU.

Federal Emergency Management Agency, Disaster Mittigation Guide for Business and Industry, FEMA 190, February 1990, 1990-719-571/10908, Washington, D.C.: U.S. Government Printing Office.

HUEY, L., (compiler), Overview of Earthquake Hazard Reduction in the Central United States: A Reader on Earthquake Hazard Reduction in the Central United States to Accompany Training Courses, 1990, Open-File Report 90-94, Reston, Virginia: U.S. Geological Survey.

KUNREUTHER, H., "Earthquake Insurance as a Hazard Reduction Strategy: The Case of the Homeowner, in Socioeconomic Impacts, Monograph No. 5, National Earthquake Conference: Activity of the International Decade for Natural Disaster Reduction, May 1993, pp. 191-210, Memphis, Tennessee.

National Institute of Building Sciences, Strategies and Approaches for Implementing a Comprehensive Program to Mitigate the Risk to Lifelines from Earthquakes and Other Natural Hazards, A report to FEMA, prepared by the Ad Hoc Panel on Lifelines, June 1989, Washington, D.C.: Federal Emergency Management Agency.

Pennsylvania Department of Community Affairs, A Special Report: Dangerous Materials and Substances and Flood Plain Management Regulations, Flood Plain Management Division Information Series, August 1988.

QUARANTELLI, E.L., Similarities and Differences in Institutional Response to Natural and Technological Disasters, Disaster Research Center, Preliminary Paper \#147, 1990, Newark, New Jersey: University of Delaware.

SHOWALTER, P.S. and MYERS, M.F., "Natural Disasters in the United States as the Release Agent of Oil, Chemicals, or Radiological Materials Between 1980-1989: Analysis and Recommendations", Risk Analysis, 14(2), 1994, pp. 169-182.

SHOWALTER, P.S. and MYERS, M.F., Natural Hazards as the Cause of Technological Emergencies: A Review of the Decade 1980-1989, Working Paper No. 78, Natural Hazards Research and Applications Information Center, 1992, Boulder, Colorado: University of Colorado, $120 \mathrm{pp}$.

TIERNEY, K.J., "Earthquake-Generated Hazardous Materials Releases: Research and Policy Issues” in Proceedings of the 2nd Japan-United States Workshop on Urban Earthquake Hazards Reduction, Shimizu, Japan, July 27-29, 1988, pp. 248-250, Japan: Institute of Social Safety Science; U.S.: Earthquake Engineering Research Institute.

TIERNEY, K.J., “Secondary Hazards Resulting from Earthquakes: Hazardous Materials Emergencies and High-Rise Fires, Urban Resources 5(4), 1988, pp. 33-36.

U.S. General Accounting Office, Report and Testimony: July 1991, GAO/OPA-91-12, 1991, Washington, D.C. : Office of Public Affairs.

ZEIGLER, D.J., JOHNSON, Jr. and BRUNN, S.D., Technological Hazards, Resource Publications in Geography, 1983, Washington, D.C.: Association of American Geographers. 